\title{
OS PROGRAMAS DE ACELERAÇÃO SULAMERICANOS E SEU PAPEL NO DESENVOLVIMENTO DE EMPREENDEDORES DE NEGÓCIOS INOVADORES.
}

Charles Bonani De Oliveira ${ }^{1}$ José Marques Pereira Junior ${ }^{1}$

${ }^{1}$ Administração / Administração / ESE - Escola Superior de Empreendedorismo SEBRAE-SP 


\section{OS PROGRAMAS DE ACELERAÇÃO SULAMERICANOS E SEU PAPEL NO DESENVOLVIMENTO DE EMPREENDEDORES DE NEGÓCIOS INOVADORES.}

\section{Resumo}

Neste trabalho serão analisados os programas de aceleração de startups de maior relevância nos países sul-americanos. O objetivo principal é evidenciar as principais similaridades e diferenças na formatação dos programas e perfil dos projetos selecionados, bem como na formação do perfil empreendedor, capaz de gerar o empreendedorismo de alto impacto. Além disso, o estudo buscou analisar a contribuição desses programas no fomento ao desenvolvimento socioeconômico local. Além da fundamentação teórica acerca dos aspectos relevantes do tema, foram utilizadas como bases metodológicas pesquisas qualitativas exploratórias, por meio de estudos de casos, sendo sustentadas por análises de editais dos processos seletivos dos programas de aceleração, assim como pesquisas das bases de informações disponíveis sobre as aceleradoras da analisadas. Os resultados revelam que há um crescimento da importância das aceleradoras como atores fundamentais no fomento ao desenvolvimento local, em especial nos países sul-americanos, que buscam alternativas para gerar inovações, renda e emprego.

Palavras-chave: Startups, Programas de Aceleração, Inovação, Ecossistema de Startups Sul-Americanos.

\section{INTRODUÇÃO}

Ao analisar a efetividade dos programas de aceleração de startups na transformação e fomento ao ecossistema empreendedor constata-se suas capacidades de auxiliarem na estruturação e consolidação de modelos de negócios inovadores, que apresentem em sua grande maioria uma taxa de crescimento exponencial e sustentável no médio e longo prazo (Blank, 2010), contribuindo, seguindo a ótica de Schumpeter (1939), para a geração de ciclos de desenvolvimento econômico. Além disso, a compreensão do papel e do nível de interação que os programas de aceleração mantêm junto aos atores envolvidos no processo são essenciais para a análise de suas contribuições aos indicadores de avanço tecnológico e econômicos das regiões onde estão localizadas essas iniciativas (Souza, 2017)

Muito mais do que seguir uma tendência global acerca do fenômeno do crescimento do número de startups e do fascínio causado pela associação entre tecnológica e inovação, o incentivo às iniciativas que promovam esses modelos de negócios é uma saída estratégica para o desenvolvimento de regiões até então restrita aos modelos econômicos e fontes de receita e riqueza decadentes, mas com alto potencial de desenvolvimento por meio da combinação entre empreendedorismo, conhecimento e avanços tecnológicos (CORFO, 2016).

$\mathrm{O}$ artigo se justifica pelo crescimento recente da importância da geração de renda e emprego nos países sul-americanos, a partir de modelos de negócio que se iniciaram do desenvolvimento de startups, mesmo diante de um cenário desfavorável vivenciado por essas economias, com queda nos volumes de investimento, baixa atividade interna, déficits primários e ampliação do desemprego (CEPAL, 2017). Nesse sentido, as aceleradoras se tornaram atores estratégicos por conduzirem os participantes de seus programas numa trajetória mais assertiva de validações e mitigações dos riscos inerentes à criação de negócios inovadores. 
Desta forma, o artigo se propõe a responder quais são as principais similaridades e diferenças desses programas e principalmente qual a contribuição deles na formação do perfil empreendedor, capaz de gerar o empreendedorismo de alto impacto no que se refere à promoção do emprego e da renda locais.

Além disso, o artigo busca trazer contribuições sobre a análise da expansão dos programas de aceleração de startups no bloco sul-americano, como fomentadores do desenvolvimento socioeconômico local.

$\mathrm{O}$ artigo está estruturado em cinco seções além da introdução. $\mathrm{Na}$ primeira, será apresentada a fundamentação teórica sobre os aspectos mais relevantes do ecossistema de Startups, bem como abordará as definições, similaridades e distinções entre programas de aceleradoras e de incubadoras. $\mathrm{Na}$ segunda, serão apresentados problemas de pesquisa e os objetivos que serão observados ao longo da pesquisa. Na terceira seção serão trabalhados os aspectos metodológicos da pesquisa. A quarta seção apresentará os resultados da pesquisa, trazendo os programas de aceleração sul-americanos conforme os critérios de escolhas e suas características. Na quinta parte estão os resultados sobre as análises dos programas sulamericanos de aceleração de startups. E concluindo na última seção serão apresentadas as considerações finais, e sugestões para futuros estudos.

\section{FUNDAMENTAÇÃO TEORICA}

\section{estão inseridas \\ 2.1: O que são startups e como é constituído o ecossistema empreendedor no qual}

Segundo Ries (2012), uma startup “[...]é uma organização humana projetada para criar novos produtos e serviços sob condições de extrema incerteza". Blank \& Dorf (2014) complementam essa definição destacando que startups são organizações temporárias, na busca de um modelo de negócios que seja confiável, repetível e escalável, capaz de trazer grandes oportunidades e desenvolvimento para o meio onde estão inseridas. Portanto, para o presente trabalho, a definição de startup pode ser resumida como sendo uma instituição em busca de minimizar os riscos e incertezas inerentes ao processo de criação de modelos de negócios, sobretudo aqueles inovadores, cujo entendimento do segmento de clientes, das suas necessidades e expectativas são aspectos de relevância crítica para o sucesso do empreendimento. Esse processo de estruturação de modelos de negócios é entendido como validação, onde a startup se utiliza do mínimo de recursos possíveis para encontrar o melhor ajuste entre a solução desenhada e a necessidade do mercado (Blank \& Dorf, 2014; Maurya, 2012; Ries, 2010).

É nesse sentido que o termo "aceleradora" se justifica, por se utilizar de métodos de atuação estruturados, redes de contatos e mentorias direcionadas para diminuir esse tempo de validação, "acelerando" o desenvolvimento do projeto para as etapas posteriores de execução do negócio.

Além dos empreendedores (founder), startups e aceleradoras, outros atores são fundamentais para a existência desse ecossistema empreendedor, sendo divididos em tangíveis como incubadoras, mentores, investidores, instituição de fomento à inovação e empreendedorismo, universidades, centros de pesquisa e parques tecnológicos, e intangíveis que estão mais ligados ao conhecimento, porém são responsáveis pelo início do processo de estruturação de negócios, como ideias, habilidades e atitudes empreendedoras (Aleisa, 2013 apud Souza e Torres, 2016, pg. 386).

Organizadores:


Souza \& Torres (2016) estabeleceram uma analogia entre o ecossistema empreendedor e o biológico. Para eles, um ecossistema se pressupõe de elementos que mantenham relações harmônicas, por vezes simbióticas, competição e mutualismo. Quando ocorre a falta, a extinção ou mesmo a inexistência de algum dos atores que o compõe ocorre um desequilíbrio no meio, afetando diretamente os outros elementos.

Colin (2015) contribui com essa linha de pensamento ao abordar sobre os elementos essenciais para a formação do ambiente empreendedor, sendo eles capital, conhecimento e "rebelião". Para ele, esse último elemento é o agente catalisador necessário para ocorrer a transformação de todo o processo de desenvolvimento de novos negócios, por tirar os atores da zona de conforto e transformá-los em empreendedores na busca pelo protagonismo, realização e geração de inovação, riqueza e impacto social. Essa abordagem vai de encontro com a visão "schumpeteriana" de empreendedor inovador, ou seja, aquele que transforma o meio por gerar novos produtos, serviços ou modelos de negócio e serão seguidos por outros, promovendo ciclos de prosperidade decorrentes da ampliação dos volumes de investimentos que ativam a economia e geram o aumento da renda e do nível de emprego (Shcumpeter, 1939).

\section{2 . Aceleradoras de Startups: Definições e Origens}

Para André et al (2014) e Fishback (2007) aceleradoras são compostas por grupos de pessoas, geralmente empresários com experiências de mercado, que prestam serviços de apoio, cedem espaços físicos e disponibilizam orientações, mentorias, redes de contato, serviços de gestão, conhecimento e expertise para os projetos participantes dos programas. O objetivo delas é dar suporte aos projetos selecionados e ajudá-los a terem sucesso nas primeiras fases do negócio, onde os riscos são maiores. Esses empreendimentos estão comumente estabelecidos em um ambiente incerto e volátil, com a intenção de trazer uma nova oportunidade de negócio para o mercado. Além disso, as aceleradoras possuem alianças estratégicas com outras empresas específicas com as quais estão familiarizadas e possuem boas referências, como fundos de venture capital, por exemplo. (ANDRE et al, 2014)

Segundo Fishback (2007), a primeira aceleradora lançada foi a "The Foundry Inc.", criada em1998. Localizada na Califórnia, ela tinha como objetivo oferecer suporte ao surgimento de empresas direcionadas para o desenvolvimento de equipamentos médicos e hospitalares. Segundo o autor, ela se uniu a dois fundos de venture capital, Morgenthaler Ventures e Split Rock Partnes, levantando o montante de quase 200 milhões de dólares em investimentos. Juntas elas aceleraram mais de 10 companhias que alcançaram o mercado, movimentaram mais de 2 bilhões de dólares e geraram mais 500 empregos diretos (Foundry Inc., 2018).

ANDRE et al (2014) ao mencionar Miller e Bound (2011) trazem como principais características de um programa de aceleração: 1) Um processo de aplicação aberta, mas altamente competitivo; 2) Prestação de investimento semente, geralmente em troca de participação acionária (equity); 3) Um foco em pequenas equipes e não indivíduos; 4) Apoio por tempo limitado compreendendo os eventos programados e orientação intensiva com foco da definição do modelo de negócio; e 5) Startups recebendo apoio em lotes de acordo com a estratégia ou natureza da aceleradora e 6) aplicação de metodologias voltadas para desenvolvimento da cultura de execução.

Ribeiro et. al (2015) ampliaram o entendimento desses programas ao trazerem suas contribuições para o cenário brasileiro, destacando que as aceleradoras existentes no país se caracterizam por oferecerem uma estrutura de suporte aos negócios nascentes, por três meios: a) recursos diversos, como capital, infraestrutura, equipe de apoio e redes de contatos; b)

Organizadores:


mentorias intensivas centradas no refinamento do modelo de negócios; e c) métodos próprios voltados para desenvolvimento da cultura de execução, com vista ao alcance de mercado.

\subsection{O que diferencia aceleradoras e incubadoras de empresas}

Há no mercado uma confusão acerca da diferença entre aceleradora e incubadora, sobretudo nos aspectos ligados ao papel desempenhado, atuação, suporte, financiamento e estágio de maturação dos projetos atendidos. Esse entendimento ocorre devido ao foco de atuação dos programas visarem o suporte aos projetos que se encontram nas fases iniciais de estruturação.

Ao estudar esses dois modelos, Ribeiro et. al. (2015) destacaram que os programas de incubação possuem uma duração de até três anos, fornecem infraestrutura e acesso aos centros de pesquisas e laboratórios nas universidades, com foco no desenvolvimento de produtos. Além disso, carecem de mentores com visão de mercado que possam dar uma contribuição mais ampla sobre os ajustes técnicos ou do modelo de negócio almejado. Porém, os programas de incubação estão mais estruturados no suporte à gestão e ao acesso aos programas de bases tecnológicas e de subvenção econômica, bem como fornecem infraestrutura com custo subsidiado, que na maioria dos casos há contrapartida da empresa ou projeto.

No que se refere aos programas de aceleração, eles possuem um menor tempo de duração, mas se desenvolvem com maior intensidade de ações, com forte atuação da rede de mentores que visam trazer maturidade e validação à visão inicial dos empreendedores quanto ao mercado que estão se posicionando (RIBEIRO et. al, 2015 p.16). Além disso, os programas são geralmente subsidiados por capital privado e estão focados no suporte aos projetos que se encontrem nas fases de validação e tração com vista ao alcance da escalabilidade de suas receitas e número de clientes (Sebrae/ABStartups, 2013).

\section{PROBLEMA DE PESQUISA E OBJETIVOS}

Estima-se que somente o mercado de startups no Brasil movimenta cerca de R\$ 2 bilhões em negócios e gera mais de 1.000 postos de trabalho (ABStartups, 2014). Neste sentido ao analisar o cenário das aceleradoras verificou-se que há um forte movimento de expansão dos programas e projetos apoiados, iniciado em 2010 (FUNDACITY, 2015). Ribeiro et. al, (2015) e Fundacity (2015) mostram que das 62 iniciativas mapeadas na América Latina, mais de 80\% estão localizadas nos países sul-americanos, com destaque para o Brasil que representa cerca de $50 \%$ desse total.

Diante disso, o objetivo principal do presente trabalho é analisar as principais similaridades e diferenças entre os programas de aceleração sul-americanos. Além disso, pretende verificar se eles contribuem para o fomento da renda e emprego local, promovendo o empreendedorismo de alto impacto.

O estudo também busca verificar: i) os pontos de convergência entre os programas Sulamericanos; ii) o posicionamento do Brasil nesse cenário; e iii) se existem programas que tenham como foco a formação atitudinal do empreendedor (founder) e se esse é um fator crucial para alcançar uma taxa de êxito maior quando comparados com aqueles que não apresentem esse viés.

\section{METODOLOGIA}

O presente trabalho é um estudo sobre os programas de aceleração de startups dos países sul-americanos. Do ponto de vista da abordagem dos objetivos, este estudo se apresenta como qualitativo exploratório (Chizzotti, 2006), onde busca-se aprofundar o entendimento sobre a

Organizadores:

Realizadores:

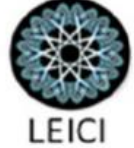


problemática e torna-la mais explicita se utilizando de pesquisas bibliográficas e estudos de casos (Gerhardt e Silveira, 2009; Yin, 2001; Eisenhardt, 1989).

Para Tachizawa (2015), na abordagem de estudo de caso, o artigo deve ser desenvolvido a partir de uma análise detalhada das organizações ou programas enfocados, sendo esta, segundo o autor, a situação mais comum, por trazer uma análise interna das ações propostas corroborando para uma análise mais aprofundada dos programas analisados.

\subsection{Critérios da escolha dos Programas}

O critério principal utilizado para a escolha dos programas selecionados como objeto deste estudo foi o posicionamento deles frente ao ranking mapeado pela Fundacity, uma plataforma que tem como proposta de valor mapear todos os atores do ecossistema de startups nos diferentes locais no mundo, neste caso em especifico, aqueles localizados nos países sulamericanos. Cabe destacar que a plataforma Fundacity foi adquirida pela Gust no ano de 2016, uma plataforma norte-americana com a mesma proposta de valor, ampliando a base de dados de pesquisa para 40 mil startups, 64 mil usuários cadastrados e presença em mais de 170 países (GUST, 2018).

A fonte principal de informações utilizada foi o Accelerator Report Fundacity, relatório de acompanhamento de aceleradoras e programas, em termos de localização, financiamento e abrangência, dos anos de 2014 e 2015. Cabe destacar que no relatório constam 62 organizações qualificadas como aceleradoras, que compartilharam suas informações com a plataforma, agregando mais informações ao ecossistema (FUNDACITY, 2015).

Além disso, utilizou-se como fontes complementares os repositórios acadêmicos ProQuest, EBSCO e Biblioteca Brasileira de Teses e Dissertações (BDTD), além de sites de referências que fazem o monitoramento do ecossistema startup no mundo.

\subsection{Limitações da pesquisa}

Um fator limitador importante está relacionado aos aspectos políticos e socioeconômicos, como alguns programas que foram descontinuados devido à perda do patrocínio de seus mantenedores. Exemplo disto foi o programa de aceleração da SEED-MG, considerada uma das principais referências sul-americanas na modalidade de aceleração, em 2014. Porém, no ano de 2015 foi descontinuado por se tratar de uma iniciativa governamental e, com a não continuidade do governo que o implementou, encontrou dificuldades burocráticas para dar continuidade no ano de 2015.

\section{RESULTADOS DA PESQUISA}

Os programas de aceleração se tornaram uma forma comprovada de rápido crescimento para uma startup, que encontram direcionamentos em seus processos de estruturações de seus modelos de negócios, muito em função da rede de contatos com especialistas e mentores proporcionada pelas aceleradoras (Fundacity, 2016; Fischback, 2009). Além disso, os relatórios destacaram que os aportes de recursos financeiros são essenciais para que as equipes possam viabilizar o início das operações de suas startups (FUNDACITY, 2016).

Outro ponto de destaque neste mesmo relatório é a expansão dos programas promovidos na América Latina, passando de 53 para 62, entre 2014 e 2015, conforme evidenciado pelo gráfico abaixo. Além disso, o aumento expressivo do número de startups atendidas, que passou de 872 para 1.333, no mesmo período, reforça o fortalecimento desse ecossistema. Os países sul-americanos representam $24 \%$ do total de programas de aceleração e $73 \%$ do número de startups atendidas. Isso indica que os programas sul-americanos possuem um perfil mais massificado, buscando atender um maior número de projetos.

Organizadores:


Gráfico 1 - Número de Aceleradoras Latino-Americanas e Startups Aceleradas

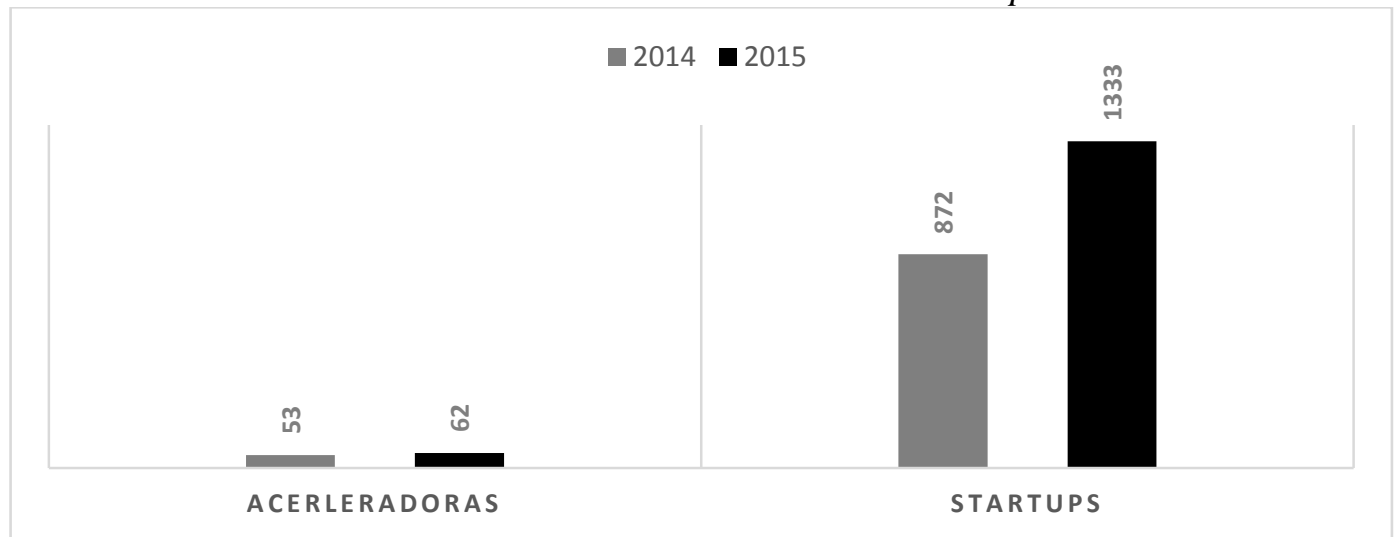

Fonte: Adaptadado de Fundacity 2014/2015.

Um aspecto negativo foi a queda de cerca de $11 \%$ do volume de investimentos aportados nos programas latino-americanos de aceleração, que passaram de US\$35,3 milhões em 2014 para US\$31,5 milhões em 2015, conforme destacado no gráfico abaixo:

Gráfico 2 - Investimentos em Programas de Aceleração Latino-Americanos (US\$ milhões)

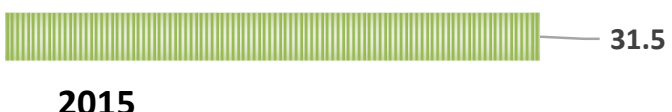

2015

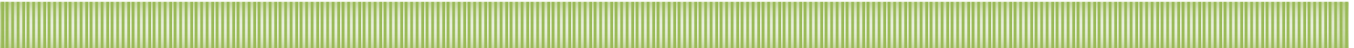

2n14

29

30

31

32

33

34

35

Fonte: Fundacity 2014 e 2015

Analisando somente os países sul-americanos, a tabela abaixo demonstra a relevância do bloco na contribuição aos investimentos voltados para os programas de aceleração, que somente no ano de 2015 movimentou cerca de US\$ 28,2 mi e respondeu por mais de $90 \%$ de todos os programas da América Latina. Esse resultado pode ser um indicativo de que os países periféricos têm buscado alternativas junto ao ecossistema de startup para fazer frente aos resultados ruins apresentados pelos setores tradicionais como indústria e agricultura (Startup Chile, 2015). 
Tabela 1 - Investimentos em programas de aceleração de startups nos países sulamericanos, ano de 2015

\begin{tabular}{l|c|l|l}
\hline & US\$ & Startups Aceleradas & Programas \\
\hline Chile & 15.096 .929 & 442 & 14 \\
\hline Brasil & 5.524 .320 & 297 & 26 \\
\hline Uruguai & 4.373 .900 & 105 & 6 \\
\hline Argentina & 2.385 .700 & 61 & 7 \\
\hline Colômbia & 328.400 & 67 & 5 \\
\hline Venezuela & 265.000 & 32 & 3 \\
\hline Peru & 257.000 & 13 & 1 \\
\hline Paraguai & 20.000 & 10 & 1 \\
\hline
\end{tabular}

Fonte: Elaboração própria a partir de dados dos Relatórios Fundacity/Gust 2015 e 2016.

O quadro abaixo destaca a representatividade de cada país sul-americano em termos de número de programas, volume de investimento recebido e quantidade de startups aceleradas, entre os anos de 2014 e 2015 :

\begin{tabular}{|l|c|c|c|c|c|c|}
\hline \multicolumn{7}{|c|}{ Tabela 2 - Os países sul-americanos mais ativos em Quantidade de Programas, } \\
Startups e Investimento \\
\hline \multirow{2}{*}{ Pais } & \multicolumn{3}{|c|}{$\mathbf{2 0 1 4}$} & \multicolumn{3}{c|}{$\mathbf{2 0 1 5}$} \\
\cline { 2 - 7 } & $\mathbf{N}^{\mathbf{o}}$ Progr. & $\begin{array}{c}\text { Investimento } \\
\text { (US\$ mi) }\end{array}$ & Startups & $\mathbf{N}^{\mathbf{0}}$ Progr. & $\begin{array}{c}\text { Investimento } \\
\text { (US\$ mi) }\end{array}$ & Startups \\
\hline Chile & $\mathbf{3}$ & 11,2 & 297 & $\mathbf{5}$ & 15,1 & 442 \\
\hline Brasil & $\mathbf{7}$ & 11,4 & 265 & $\mathbf{2}$ & 5,5 & 297 \\
\hline Argentina & $\mathbf{6}$ & 3,1 & 83 & $\mathbf{6}$ & 2,3 & 61 \\
\hline Uruguai & $\mathbf{1}$ & 0,6 & 23 & $\mathbf{1}$ & 4,3 & 105 \\
\hline Colombia & $\mathbf{1}$ & 0,8 & 17 & $\mathbf{1}$ & 0,3 & 67 \\
\hline
\end{tabular}

Fonte: Elaboração própria a partir de Fundacity (2014/2015).

Em termos de volume de investimentos total, houve um ligeiro crescimento, saindo de US\$ 27,1 mi para US\$27,7 mi, entre os anos de 2014 e 2015. Porém, a quantidade de programas de aceleração foi reduzida, saindo de 18 para 15. Apesar disso, houve um crescimento de cerca de $42 \%$ do número de startups atendidas. Isso reflete a ampliação dos programas, que passaram a expandir seus atendimentos, mas teve como consequência uma maior diluição do aporte médio por startup. Esses resultados podem refletir numa queda da efetividade dos programas em termos de auxílio no alcance do mercado pelos projetos apoiados, já que apoio financeiro foi destacado com um dos fatores essenciais nas fases iniciais dos projetos (Fundacity, 2015).

Verifica-se que o Brasil era o principal representante entre os países sul-americanos no ano de 2014, em termos de volume de investimento e quantidade de programas de aceleração, seguido de Chile e Argentina. Porém, esse quadro foi revertido em 2015, com uma queda considerável do volume de investimento, tanto por parte do Brasil como da Argentina. No caso brasileiro, a perda de representatividade foi ainda maior pela queda do número de programas de aceleração realizados. Esse processo conduziu o país para a segunda posição em termos de volume de investimento e terceira na quantidade de programas.

Cabe destacar o importante crescimento apresentado pelo Chile no período, que junto com o Uruguai, foram os únicos a apresentarem crescimento do volume de investimentos. Além disso, o Chile teve crescimento da quantidade de programas e quase dobrou o número de startups aceleradas, entre os anos de 2014 e 2015. Esses resultados colocaram o país em posição 
de liderança na região, evidenciando a consolidação do trabalho desempenhado pelo ecossistema de startups local.

Outro país que merece destaque é o Uruguai, que apresentou um crescimento maior que $700 \%$ do volume de investimentos no período. Além disso, ampliou o número de startups atendidas em quase $400 \%$. Com esse resultado, o país saiu da última colocação e passou a ser o terceiro colocado na região. Outro ponto de destaque é que o país apresentou o maior aporte médio por startup, para o ano de 2015, com um volume de US\$ 41,6 mil.

Apesar da queda apresentada no período, a Argentina continua sendo um importante ator nesse ecossistema, sobretudo pela manutenção do número de programas de aceleração e ampliação do aporte médio por startup.

Dando continuidade às análises, as seções seguintes trabalharão os programas de maior destaque entre os países sul-americanos.

\section{PROGRAMAS DE ACELERAÇÃO DE STARTUPS PRESENTES NOS PAÍSES SULAMERICANOS}

Tendo como objetivo aprofundar as análises sobre os programas de aceleração de startups realizados nos países sul-americanos, as próximas seções buscarão elucidar acerca dos diferenciais, similaridades e impacto socioeconômico.

Essas análises e discussões serão embasadas nos dados coletados dos programas de maior relevância, segundo Fundacity (2015).

\subsection{Convergência e diferencias dos Programas de Aceleração Sul-americanos.}

Para analisar os pontos de convergência e os diferenciais dos programas de aceleração presentes na América do Sul, foram analisados os trabalhos realizados por cinco aceleradoras distintas: Startup Chile, Startup Farm, Ideas Factory, EmpreendeCH e HubBog, que juntas responderam por 20 edições de programas e por cerca de 40 por cento do número total de startups atendidas por todos os programas sul-americanos, no ano de 2015. Cabe destacar que essas aceleradoras foram analisadas por apresentarem continuidade das ações nos anos de 2014 e 2015, uma vez que alguns programas foram descontinuados e outros passaram a ter relevância apenas em 2015, como é o caso da Seed (Brasil) no relatório de 2014 e a Softlands (Uruguai) em 2015 (Fundacity, 2015 e 2016).

A tabela 2 abaixo traça as comparações entre os cinco principais programas, dando ênfase na sazonalidade, duração, concorrência e eficiência.

\begin{tabular}{|c|c|c|c|c|c|c|c|c|}
\hline \multicolumn{9}{|c|}{ Tabela 3 - Principais programas de aceleração sul-americanos 2014 e 2015} \\
\hline Aceleradora & Financiamento & País & Estágio ${ }^{1}$ & $\begin{array}{c}\text { Duração } \\
\text { (mês) }\end{array}$ & $\begin{array}{c}\text { Programas } \\
\text { em } 2015\end{array}$ & $\begin{array}{l}\text { Projetos } \\
\text { Inscritos }\end{array}$ & $\begin{array}{c}\text { Projetos } \\
\text { Selecionados }\end{array}$ & $\begin{array}{c}\text { Projetos } \\
\text { Graduados }\end{array}$ \\
\hline Ideas Factory & Privado & Argentina & I e II & 6 & 6 & $<200$ & 51 a 100 & 21 a 50 \\
\hline Startup Chile & Público/Privado & Chile & I, II e III & 6 & 2 & $>1.000$ & $>151$ & 101 a 150 \\
\hline Startup Farm & Privado & Brasil & I e II & 2 & 4 & $>1.000$ & 51 a 100 & 51 a 100 \\
\hline
\end{tabular}

\footnotetext{
${ }^{1}$ Os estágios estudados são: I. Pré-aceleração, que trabalham os projetos em fase de ideação; II. Aceleração, que visam potencializar as validações dos modelos de negócio com vista ao ajuste entre produto e mercado; e III. Escala, onde já se possui o ajuste entre produto e mercado e busca-se alcançar o crescimento e escalabilidade do negócio.

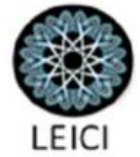




\begin{tabular}{|c|c|c|c|c|c|c|c|c|}
\hline EmpreendeFCh & Público/Privado & Chile & I e II & 1 & 4 & $\begin{array}{l}751 \text { a } \\
1.000\end{array}$ & $>151$ & 21 a 50 \\
\hline HubBog & Privado & Colômbia & I e II & 3 & 4 & $\begin{array}{l}751 \text { a } \\
1.000\end{array}$ & 101 a 150 & 21 a 50 \\
\hline
\end{tabular}

Fonte: Elaboração própria a partir de Fundacity (2014/2015).

Em geral, os programas de aceleração possuem cronogramas intensivos, apresentando duração de até seis meses. Nesse intervalo de tempo, os aspectos mais evidenciados são a estruturação do modelo do negócio, direcionamento de mentorias para aspectos específicos com especialistas de mercado e ampliação de networking.

Um ponto comum às aceleradoras é a realização de programas de pré-aceleração em sua base. Isso se deve à necessidade de ampliar o escopo de projetos na base de entrada dos programas e realizar uma melhor estruturação dos proponentes, sobretudo nas etapas iniciais de validação. Além disso, a Startup Chile realiza programas de pós-aceleração que visam dar escalabilidade aos projetos que apresentem maior maturidade na conquista do mercado.

A maior parte dos recursos destinados ao financiamento dos projetos acelerados vem de recursos privados, tendo como objetivo a obtenção de uma boa taxa de retorno quando do processo de saída (cash out), onde novas rodadas de investimentos ocorrem. Porém, existem vários programas que contam com a colaboração de capital público não-reembolsável. Nesse caso, o objetivo dos governos é fomentar ciclos virtuosos da economia, promovendo a renda e o emprego. Além de colaborar com o surgimento de novos segmentos da economia (CORFO, 2015).

Na média, os projetos acelerados por esses programas recebem cerca de US\$30 mil em troca de um equity do negócio. Esses recursos podem ser de duas formas: financeiro, com a disponibilização de dinheiro aos participantes; e econômicos, também conhecido como smart money, modalidade na qual as aceleradoras concedem seu corpo técnico para desenvolver parte do projeto.

A concorrência por uma vaga num dos programas das principais aceleradoras é bastante elevada, se situando na maioria dos casos numa concorrência de 10 projetos candidatos por vaga, elevando o rigor da seleção e o ingresso de projetos que já estejam num estágio mais avançado de validação.

Outro resultado importante que pode ser constatado é a efetividade dos programas com relação ao alcance de seus objetivos, quer seja, a graduação de uma startup. Esse processo representa que o projeto conquistou maior maturidade e o ajuste entre solução e mercado está mais assertivo e preciso. Nos casos analisados, a taxa de graduação dos programas varia entre $30 \%$ e $50 \%$ dos projetos selecionados. Nesse sentido, como sugestão para estudos futuros, se torna interessante a análise sobre os fatores principais que permitem a alguns programas serem mais efetivos.

Outros aspectos de destaque sobre os programas podem ser apresentados na Tabela 03, ao retratar as linhas gerais dos programas acerca do perfil dos projetos que as aceleradoras buscam, formato dos programas e a contribuição à formação empreendedora de seus participantes durante sua participação.

Verificou-se que os programas possuem como foco comum a utilização da tecnologia da informação e comunicação por parte dos projetos, como forma de gerar, entregar ou capturar valor junto ao público-alvo pretendido por eles. Porém, alguns dos programas, sobretudo aqueles patrocinados pela iniciativa pública, buscam atender demanda de áreas específicas, 
como forma de gerar novos conhecimentos, novas oportunidades de negócio ou inovações tecnológicas que auxiliem no desenvolvimento socioeconômico.

Por fim, uma das proposições desse estudo foi analisar os programas de aceleração com relação à contribuição na formação do empreendedor, sobretudo nos aspectos atitudinais, uma vez que recai sobre o founder e seu time a missão de estruturar o negócio de maneira que ele se torne rentável (BLANK, S. \& DORF, B, 2014). A questão neste momento é a real necessidade de haver um empreendedor cada vez mais preparado para assumir suas responsabilidades perante uma sociedade cada vez mais demandante de pessoas com este perfil, e uma economia cada vez mais dinâmica que precisa se reinventar com o foco nos avanços tecnológicos e mercadológicos.

A relevância da formação destes empreendedores em seus aspectos atitudinais é vista como uma das principais variáveis para o alcance dos resultados de alto impacto, sendo possível retratar não somente as necessidades pessoais e de sobrevivência do founder, mas principalmente as oportunidades observadas e aproveitadas por esses empreendedores nos ambientes em que estão inseridos, conforme fora bem retratado em Ribas (2011) e Endeavor Insight (2014).

Os programas destacaram que a postura do empreendedor e sua apresentação para o mercado são considerados no momento da seleção dos projetos. Apesar disso, os programas negligenciam esses aspectos ao longo da aceleração, com exceção da Ideas Factory, que dá ênfase na capacitação em diferentes habilidades e comportamentos específicos, inclusive associando-os às inteligências emocionais. O programa incluí, ainda, um acompanhamento coaching, com o intuito de alcançar uma maior performance dos projetos. 


\section{Frecose}

\begin{tabular}{|c|c|c|c|}
\hline $\begin{array}{c}\text { Nome da } \\
\text { Aceleradora } \\
\text { (Origem) }\end{array}$ & Foco dos projetos acelerados & Perfil do Principal Programa de Aceleração & $\begin{array}{l}\text { Quais fatores que evidencia a relevância dada a formação e o } \\
\text { preparo dos participantes em seus aspectos atitudinais? }\end{array}$ \\
\hline $\begin{array}{l}\text { Ideas Factory } \\
\text { (Argentina) }\end{array}$ & $\begin{array}{l}\text { As bases são multissetoriais mas } \\
\text { atualmente têm projetos } \\
\text { específicos na área da saúde e agro } \\
\text { negócios. }\end{array}$ & $\begin{array}{l}\text { O programa possibilita que o projeto tenha um patrocinador } \\
\text { e/ou investidor anjo. Além disso, fornece orientações e } \\
\text { capacitação, incubação física durante } 6 \text { meses, pré- } \\
\text { aceleração do projeto/ideia, a participação no demo Day } \\
\text { contra os diferentes atores para avançar o desenvolvimento } \\
\text { do projeto. Podendo chegar até três anos de permanência. }\end{array}$ & $\begin{array}{l}\text { Capacitam empreendedores em diferentes habilidades ou } \\
\text { conhecimentos específicos para que possam melhorar seus } \\
\text { negócios. Neste sentido atividades associadas a Inteligência } \\
\text { emocional e coaching são trabalhados ao longo do } \\
\text { programa. }\end{array}$ \\
\hline $\begin{array}{l}\text { Startup Chile* } \\
\quad \text { (Chile) }\end{array}$ & $\begin{array}{l}\text { Projetos multissetoriais que } \\
\text { possam trazer competitividade e } \\
\text { desenvolvimento para a economia } \\
\text { chilena. }\end{array}$ & $\begin{array}{l}\text { Seed: Programa de aceleração para startups com um } \\
\text { produto funcional e validação precoce. Empresas } \\
\text { selecionadas recebem cerca de US } \$ 30 \text { mil) e } 06 \text { meses de } \\
\text { aceleração. Duas rodadas por ano de } 80-100 \text { empresas cada. }\end{array}$ & $\begin{array}{l}\text { A grade de atividades junto aos empreendedores, a SUP } \\
\text { Academy, aproveita a força da comunidade Start-Up Chile, } \\
\text { identificando talentos diferenciados e organizando } \\
\text { workshops, palestras e outras experiências de } \\
\text { aprendizagem. Possui como principal fator a comunidade } \\
\text { rica e multicultural com atores de mais de } 50 \text { países. É uma } \\
\text { oportunidade perfeita para ajustar apresentações em } \\
\text { público, superar o nervosismo do palco e dominar as } \\
\text { habilidades de comunicação. }\end{array}$ \\
\hline
\end{tabular}

Organizadores:

- fov eaesp

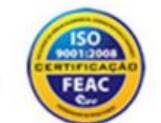

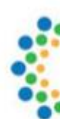

Realizadores:

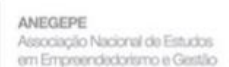

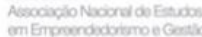

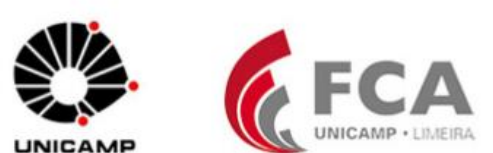




\begin{tabular}{|c|c|c|c|}
\hline & $\begin{array}{l}\text { São projetos multissetoriais no } \\
\text { entanto buscam aderência com } \\
\text { propostas e soluções que o } \\
\text { mercado demanda como IoT } \\
\text { (internet das coisas), Fintech } \\
\text { (Meios de Pagamento e Soluções } \\
\text { Financeiras), TIC, New media e } \\
\text { Mobilidade de Urbana até por } \\
\text { conta do apoio e suporte dos } \\
\text { parceiros movimentados. }\end{array}$ & $\begin{array}{l}\text { O Programa é divido em duas etapas a primeira tem } \\
\text { duração de } 5 \text { semanas onde após o programa, as startups } \\
\text { finalistas terão a oportunidade de apresentar seus projetos } \\
\text { para CEOs das maiores empresas dos setores em que atuam } \\
\text { segundo a temática do Programa. O Segundo momento é o } \\
\text { acompanhamento destas startups por cerca de dois anos } \\
\text { para efeito de amadurecimento do modelo do negócio e } \\
\text { otimização de métricas. São cerca de } 10 \text { a } 15 \text { vagas } \\
\text { disponíveis para startups. }\end{array}$ & $\begin{array}{l}\text { As startups são selecionadas de acordo com os critérios de } \\
\text { equipe e ideia. No critério equipe são considerados a } \\
\text { experiência profissional ou acadêmica dos membros e } \\
\text { complementariedade dos perfis. Já no critério ideia, são } \\
\text { avaliados a solução proposta, fundamentação do modelo de } \\
\text { negócios, grau de Inovação e concorrência. Apesar disso, } \\
\text { não há uma ação específica para trabalhar com aspectos } \\
\text { comportamentais. }\end{array}$ \\
\hline $\begin{array}{l}\text { EmprendeFCh } \\
\quad * \text { (Chile) }\end{array}$ & $\begin{array}{l}\text { São projetos multissetoriais mas } \\
\text { que tenham aderência com a } \\
\text { Proposta de desenvolvimento } \\
\text { socioeconômico apoiado pela } \\
\text { Fundacion Chile e seus parceiros e } \\
\text { apoiadores estratégicos em } \\
\text { projetos com foco em: Soluções } \\
\text { Energéticas, Sustentabilidade, } \\
\text { Alimentos, Aquicultura (Cultivo } \\
\text { de Organismos Aquáticos), }\end{array}$ & $\begin{array}{l}\text { Os projetos em estágio de Ideia são suportados através da } \\
\text { Aceleradora, financiado com recursos "fundos sementes" e } \\
\text { prestação de serviços, redes e conhecimento relevante para } \\
\text { o nascimento de negócios. Apoio constante ao } \\
\text { empreendedor para desenvolver o seu negócio e para o } \\
\text { mercado por meio de reuniões continuas para rever o } \\
\text { progresso, workshops e ferramentas de competências para o } \\
\text { empreendedorismo e eventos networking. A princípio com } \\
\text { captação mensal, mas podendo se estender para cerca de } \\
\text { dois anos. }\end{array}$ & $\begin{array}{l}\text { Ao analisar a entrada dos projetos no programa são levadas } \\
\text { em consideração o perfil e a trajetória empreendedora da } \\
\text { equipe além do nível de dedicação ao projeto e } \\
\text { comprometimento. Uma vez aceito os seus participantes } \\
\text { tem o compromisso de participar das reuniões e atividades } \\
\text { que visam melhor capacitar o empreendedor e melhorar o } \\
\text { seu pitch. Não possui ação específica para trabalhar } \\
\text { aspectos comportamentais. }\end{array}$ \\
\hline & Organizadores: & & \\
\hline
\end{tabular}




\section{Execepg}

\begin{tabular}{|c|c|c|c|}
\hline & $\begin{array}{l}\text { Mineração, Saúde, Tecnologia e } \\
\text { Varejo. }\end{array}$ & & \\
\hline $\begin{array}{l}\text { HubBog } \\
\text { (Colômbia) }\end{array}$ & $\begin{array}{l}\text { Projetos que tenham perfis de } \\
\text { Tecnologia da informação e } \\
\text { Comunicação (TIC) }\end{array}$ & $\begin{array}{l}\text { Programa de Aceleração que visa promover o } \\
\text { projeto para gerar valor e alcançar crescimento no curto } \\
\text { prazo, inovação e escalabilidade. Tem duração de } 14 \\
\text { semanas e fornece uma série de ferramentas e um processo } \\
\text { abrangente e rigorosa para trazer projetos para o próximo } \\
\text { nível com base em três pilares principais. A) } \\
\text { CRESCIMENTO; B) EQUIPE e C) PITCH. }\end{array}$ & $\begin{array}{l}\text { Tanto no programa de Pré-Aceleração quanto no } \\
\text { programa de aceleração existe um foco no desenvolvimento } \\
\text { dos times pois além das orientações estratégicas e } \\
\text { especializadas, as bases do programa visam desenvolver } \\
\text { uma estrutura organizacional sólida para suportar o } \\
\text { crescimento deste empreendimento. Além disso existe a } \\
\text { possibilidade de expansão desta rede por meio de ações em } \\
\text { missões ao exterior (Vale do Silício). }\end{array}$ \\
\hline
\end{tabular}

Fonte: Dados Coletados pelo Autor

*Informações coletadas junto a sites, documentos e entrevistas sobre os programas. (STARTUP CHILE, 2016; STARTUP FARM, 2016;(EMPRENDEFCH, 2016).

Organizadores:

- fov eaesp

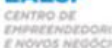

Realizadores:

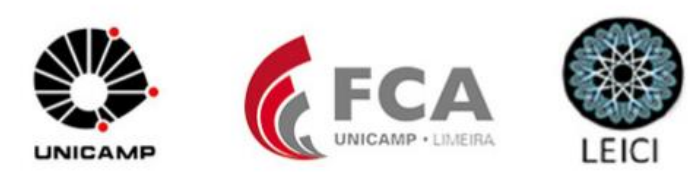


6.2. Correlação entre maturação dos projetos apoiados pelos programas de Aceleração e o retorno à sociedade como desenvolvimento socioeconômico

Ao abordar sobre a correlação existente entre volume de capital empregado nos projetos que passaram pelos programas de aceleração sul-americanos e o retorno que eles proporcionam à sociedade na forma da geração de emprego e renda, foi constatado que existem poucos dados e estudos que trabalham com esses aspectos. Cabe aqui outra sugestão para uma ampliação futura dos estudos, de forma a monitorar essas informações de forma sistemática, tendo como objetivo a justificativa dos investimentos e também analisar o impacto que esses programas promovem de fato na sociedade.

Apesar disso, o estudo realizou um esforço em juntar as informações disponibilizada pelos programas de aceleração que foram analisados.

A aceleradora Startup Chile aportou nos projetos cerca de US\$ 30,5 milhões, dos quais $29 \%$ provenientes de fundos públicos e $71 \%$ de capital privado. Segundo dados disponibilizados pela própria aceleradora, o retorno à sociedade foi da ordem de US\$ 421 milhões, representando uma taxa aproximada de $1.400 \%$. Além disso, eles mapearam um total de 5.162 postos de trabalho, sendo $30 \%$ no Chile. Os salários médios variam entre US\$1.216 e US\$ 2.280 por mês (STARTUP CHILE, 2016).

A Startup Farm estima ter captado aproximadamente US\$ 100 milhões em investimentos nos projetos por ela acelerados. Sua carteira de startups possuem uma estimativa de valor superior a US\$ 1 bilhão, ou seja, um retorno médio de 1.000\% (STARTUP FARM, 2016).

A EmprendeFCh investiu mais de US \$ 100 milhões, porém mantém os dados de retorno fechados à consulta pública (EMPRENDEFCH, 2016).

O HubBOG também traz informações sobre o número de empregos gerados. As empresas que passaram pelos seus programas de aceleração receberam US\$2,5 milhões em investimentos e geraram mais de 200 postos de trabalho.

Para alguns segmentos mais estruturados isso pode até parecer resultados modestos. Mas, apesar de incipientes, os resultados apontam para um retorno considerável à sociedade, sobretudo por serem dados de impacto direto. Além disso é importante considerar que estas iniciativas surgem de insights, exploração de oportunidades e elucubrações empreendedoras, que na maioria dos casos foram iniciados de uma ideia inovadora.

\section{CONCLUSÃO}

Os resultados das análises evidenciaram a importância do movimento de aceleradoras nos países sul-americanos, sendo que eles ocupam posição de destaque na América Latina. Apesar disso, foi constatado uma ligeira queda nos volumes de investimentos voltados ao suporte dessas startups, nos anos analisados. Esse resultado acompanhou a conjuntura vivenciada pelos países latino americanos nesse período recente, conforme abordado por CEPAL (2017). 
Os resultados indicaram que os países sul-americanos se tornaram protagonistas no que se refere aos programas de aceleração na América Latina, detendo cerca de $90 \%$ do volume de investimentos movimentados para o suporte dos projetos. Tal resultado corrobora a hipótese apresentada por CORFO (2016) de que esses países têm buscado se reinventarem para dar maior dinamismo às suas economias. Eles estão se ancorando no dinamismo do ecossistema startup, sobretudo nas iniciativas que contam com a participação dos governos como fomentadores de capitais a fundo perdido, como é o caso do Chile.

Outra averiguação importante é que os programas sul-americanos têm buscado ampliar seus escopos de atuação, com a ampliação do número de startups selecionadas por programa. Além da maior diluição dos aportes médios por projeto. Esse resultado poderá refletir num futuro próximo na queda da efetividade dos programas, que passarão a dar menor suporte individualizado.

Comparativamente, o Brasil perdeu participação na quantidade de programas realizados, startups atendidas e volume de investimentos movimentados, sobretudo pela descontinuidade de algumas iniciativas como o Seed, promovido pelo governo de Minas Gerais, que era referência entre os programas sul-americanos.

Por outro lado, houve consolidação do Chile como principal referência do ecossistema sul-americano. Muito por conta das políticas e iniciativas promovidas pelas lideranças locais. O Uruguai também merece destaque pelos esforços realizados na promoção dos programas de aceleração, conduzindo o país em posição de destaque entre os principais players da região.

Outras conclusões importantes é que os programas têm se tornado mais intensivos e focados, sobretudo na estruturação dos projetos. Além disso, a ênfase das aceleradoras e promover a base de entrada, com programas de pré-aceleração, permite que os projetos tenham maior maturidade e foco quando do ingresso na aceleração. Um grande diferencial constatado foi a maturidade com que a Startup Chile tem encarado toda a trajetória dos projetos apoiados por ela, uma vez que ela foi a única dentre as principais que promovem três estágios distintos e complementarem de aceleração.

Por fim, uma constatação negativa do presente estudo é que os programas de aceleração não têm envidado esforços na formação dos empreendedores acelerados, em especial nas habilidades e comportamentos que podem colaborar com uma melhor efetividade na conquista do mercado por parte das startups. Nesse sentido, fica uma recomendação para que os promotores dos programas passem a analisar esse aspecto como relevante e estratégico, uma vez que Blank \& Dorf (2014) destacaram que é cada vez maior a necessidade de haver um empreendedor mais preparado para assumir seu papel perante uma sociedade cada vez mais demandante de líderes com esse perfil.

\subsection{Sugestões para Futuras Pesquisas}

Ao concluir este artigo, além de sugerir uma maior ampliação desta pesquisa aos demais programas latino-americanos, pode-se trazer como orientações futuras os seguintes pontos: i). Verificar se existe correlação no crescimento ecossistemas até então incipientes como Uruguai, Chile e Peru por conta da inconsistência política e econômica enfrentadas em países como

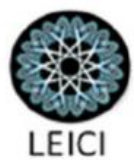


Brasil e Argentina; ii). Fazer um benchmark com os programas de aceleração mexicano, em seus aspectos positivos e seus ensinamentos onde mesmo com um volume de investimentos menor que os programas chilenos e brasileiros possuem uma grande variedade e um volume significativo de Startups aceleradas; iii). Aprofundar o foco na pesquisa dos empreendedores envolvidos nestes programas sobre suas experiências e contribuições em sua formação empreendedora e na construção de suas Startups.

\section{REFERÊNCIAS BIBLIOGRAFICAS}

ABSTARTUPS - Associação Brasileira de Startups - Mercado de startups cresce no Brasil e movimenta quase R\$ 2 bilhões - fonte acessada em 09 de junho de 2016 < http://g1.globo.com/economia/pme/noticia/2014/01/mercado-de-startups-cresce-no-brasil-emovimenta-quase-r-2-bi.html > São Paulo, 2014

ANDRE, C. et al. Orientação Empreendedora e Aceleração de Negócios: Fatores, Processos e A Consolidação de Negócios Digitais, apresentado no VIII EGEPE; Goiânia, março, 2014.

FISHBACK, B. et. al. Finding Business 'Idols': A new model to accelerate start-ups. Kauffman Foundation. 2007.

BLANK, S. \& DORF, B. - "STARTUP: Manual do Empreendedor" - Guia Passo a Passo Para Construir uma Grande Empresa. Alta Books 2014.

CEPAL (Comissão Econômica para a América Latina e o Caribe): O Balanço Preliminar das Economias da América Latina e do Caribe. Washington, 2017.

COLIN, N. What Makes an Entrepreneurial Ecosystem? The Family Papers \#000 13, Out, 2015 $<\quad$ https://salon.thefamily.co/what-makes-an-entrepreneurial-ecosystem815f4e049804\#.65zmn96ql > acesso em outubro, 2016.

CHIZZOTTI, Antonio. Pesquisa qualitativa em ciências humanas e sociais. Petrópolis: Vozes, 2006.

DA SILVA, I.M \& RAMIREZ, M.I.Q; El mercado de capital de riesgo informal en Antioquia El caso de los ángeles inversionistas y la actividad emprendedoraen Medellín., Universidad EAFIT; Medellín, 2014

DINERO. Se consolida en Bogotá campus para startups, 2015 < http://www.dinero.com/empresas/articulo/emprendimientos-apoyados-hubbog/206697 > acesso novembro 2016.

EISENHARDT, K. M. Building theories from case study research. Academy of Management Review, Mississipi, Mass., v.14, n.4, p.532-550, 1989.

EMPRENDEFCH < http://www.fch.cl/en/emprendefch/emprendimientos-startups/ > acesso em outubro, 2016.

ENDEAVOR INSIGHT (Org), OMIDYAR NETWORK - Pesquisa: Como O Vale Do Silício Se Tornou O Vale Do Silício? Três surpreendentes lições para outras cidades e regiões (Pesquisa), Endeavor Global, 2014

HUBBOG, Aceleración de Startups < http://hubbog.com/aceleracion/ > acesso outubro 2016.

FUNDACITY - Latan Accelerator Report 2014 - < http://www.fundacity.com/latamaccelerator-report-2014 > Acesso em 09 set 2015 
FUNDACITY - Latan Accelerator Report 2015 - < http://www.fundacity.com/latamaccelerator-report-2015 > Acesso em 09 set 2015

GERHARDT, T. E.; SILVEIRA, D. T. Métodos de pesquisa. Universidade Aberta do Brasil UAB/UFRGS e pelo Curso de Graduação Tecnológica - Planejamento e Gestão para o Desenvolvimento Rural da SEAD/UFRGS. - Porto Alegre: Editora da UFRGS, 2009.

IDEAS FACTORY: ¿Qué es Ideas Factory? < http://ideasfactory.la/factory.html > Acesso em novembro 2016.

OSTERWALDER, A., PIGNEUR, Y. - Inovação Em Modelos De Negócios - Business Model Generation. Alta Books, 2010.

PINHO, A. Como Funciona A Maior Aceleradora De Startups Da América Latina; Na Pratica, setembro, $2016<$ https://www.napratica.org.br/como-funciona-a-maior-aceleradora-daamerica-latina/> acesso outubro 2016.

RIBEIRO, A.T.V.B; PLONSKY G.A. \& ORTEGA, L.M. Um Fim, Dois Meios: Aceleradoras E Incubadoras No Brasil. XVI Congresso Latino-Iberoamericano de Gestão da Tecnologia ALTEC - 2015.

RIBAS. R.: A Motivação Empreendedora E As Teorias Clássicas Da Motivação. Caderno de Administração/ Revista da PUC-SP, V.5, N-1, São Paulo, 2011.

RIES, E. - A Startup Enxuta: Como os empreendedores atuais utilizam a inovação contínua para criar empresas extremamente bem-sucedidas. Tradução de Carlos Szlak, São Paulo, Leya 2012

SCHUMPETER, J. A.: Business Cycles: A Theoretical, Historical, and Statistical Analysis of the Capitalist Process. McGraw-Hill Book Company Inc., New York, 1939.

SOUZA, C. R B de \& TORRES, N.N. J: Uma Revisão da Literatura sobre Ecossistemas de Startups de Tecnologia, apresentado no XII Brazilian Symposium on Information Systems, Florianópolis, SC, May 17-20, p. 385-392, 2016

SOUZA, T. M. B. de. Programa Startup Brasil: análise da atuação em rede na implementação do programa. Trabalho de conclusão de curso (Bacharelado em Gestão de Políticas Públicas) Universidade de Brasília, Brasília, 2017.

STARTUP CHILE; Start-Up Chile's Portfolio valued in at least 1.35 billion USD < http://startupchile.org/impact/ > acesso em outubro, 2016.

STARTUP FARM; Sobre a Startup Farm - A maior e mais experiente aceleradora da América Latina, $2016<$ http://startupfarm.com.br/> acesso outubro 2016.

farm/> acesso outubro 2016.

; Sobre a Startup Farm < http://blog.startupfarm.com.br/sobre-a-startup-

TACHIZAWA, T. - Como fazer monografia na prática. 12a . Edição, Rio de Janeiro: Editora Fundação Getulio Vargas, 2015.

YIN, R.K. Estudo de Caso: Planejamento e Métodos. 2. ed. Porto Alegre: Bookman. 2001. 